\title{
First recorded co-occurrence of Valvata lewisi Currier, 1868 and Valvata lewisi ontariensis Baker, 1931 (Gastropoda: Valvatidae) from Alberta, Canada, with notes on morphometric and genetic variability
}

\author{
Robert P. Hinchliffe ${ }^{1, *}$, Cheryl Tebby ${ }^{1}$, and Tyler P. Cobb ${ }^{1}$ \\ ${ }^{1}$ Royal Alberta Museum, 9810 - 103a Avenue, Edmonton, Alberta T5J 0G2 Canada \\ *Corresponding author: robert.hinchliffe@gov.ab.ca
}

Hinchliffe, R.P., C. Tebby, and T.P. Cobb. 2019. First recorded co-occurrence of Valvata lewisi Currier, 1868 and Valvata lewisi ontariensis Baker, 1931 (Gastropoda: Valvatidae) from Alberta, Canada, with notes on morphometric and genetic variability. Canadian Field-Naturalist 133(3): 189-192. https://doi.org/10.22621/cfn.v133i3.2237

\begin{abstract}
Sympatric populations of Loosely Coiled Valve Snail (Valvata lewisi ontariensis Baker, 1931) and Fringed Valvata (Valvata lewisi Currier, 1868) are documented from Alberta, Canada, for the first time. Both forms have been identified concurrently in aquatic invertebrate survey samples collected from three wetlands in northeastern Alberta by the Alberta Biodiversity Monitoring Institute. Molecular analysis (DNA barcodes) indicates that there is no genetic distinction between $V$. lewisi (sensu stricto) and $V$. lewisi var. ontariensis. Morphometric measurements show that the degree of open coiling, the character that defines $V$. lewisi var. ontariensis, is highly variable in Alberta specimens. Our findings confirm that $V$. lewisi var. ontariensis is a phenotypic morph of $V$. lewisi.
\end{abstract}

Key words: Distribution; range extension; Alberta; Valvatidae; Valvata; Valvata lewisi; Valvata lewisi ontariensis; Alberta Biodiversity Monitoring Institute; ABMI

Loosely Coiled Valve Snail (Valvata lewisi ontariensis Baker, 1931; common name from Clarke 1981) is a tiny, enigmatic freshwater gastropod that has rarely been collected since first being described by Frank Collins Baker in 1931. Originally thought to be confined to a few locations in western Ontario, Canada (Baker 1931; Clarke 1973; Figure 1), similar specimens have since been collected as Pleistocene fossils or empty shells in Manitoba, Canada (Clarke 1973), and Minnesota, USA (Bright 1981), with the only other confirmed record of living specimens from the Cottonwood Lake Study area in North Dakota, USA (Hanson et al. 2002; Figure 1). Here, we report on the first sympatric collections of Valvata lewisi (sensu stricto) and V. lewisi var. ontariensis from Alberta, Canada, and provide notes on morphometric and genetic variability.

In contrast to the distribution of $V$. lewisi var. ontariensis, Valvata lewisi Currier, 1868 (Fringed Valvata, according to Turgeon et al. 1998) is commonly found across the prairie, parkland, and boreal regions of Canada from Newfoundland to British Columbia, north into the Yukon and Alaska, and south into the northern United States (Clarke 1981; NatureServe 2017; Figure 1). Valvata lewisi is a small freshwater snail that seldom exceeds $5 \mathrm{~mm}$ in diameter and has a depressed spire, multi-spiral operculum, and bi-pectinate gill (Clarke 1973; Burch 1982). Shell sculpting consists of fine striations on the first one and a half to two whorls, which develop on subsequent whorls into axial lamellae that are usually elevated and bladelike, but may be reduced to coarse collabral threads (Clarke 1973). In comparison, V. lewisi var. ontariensis exhibits the same characteristics, but, unlike $V$. lewisi (sens. str.) where the body whorl directly contacts the preceding whorl, $V$. lewisi var. ontariensis exhibits open coiling in which the last one to one and a half whorls are separated (Baker 1931; Figure 2).

Valvata lewisi var. ontariensis has been detected at five wetlands in Alberta, Canada, through the ongoing activities of the Alberta Biodiversity Monitoring Institute (ABMI). The ABMI collects biological information on a wide range of terrestrial and aquatic organisms across the province using 


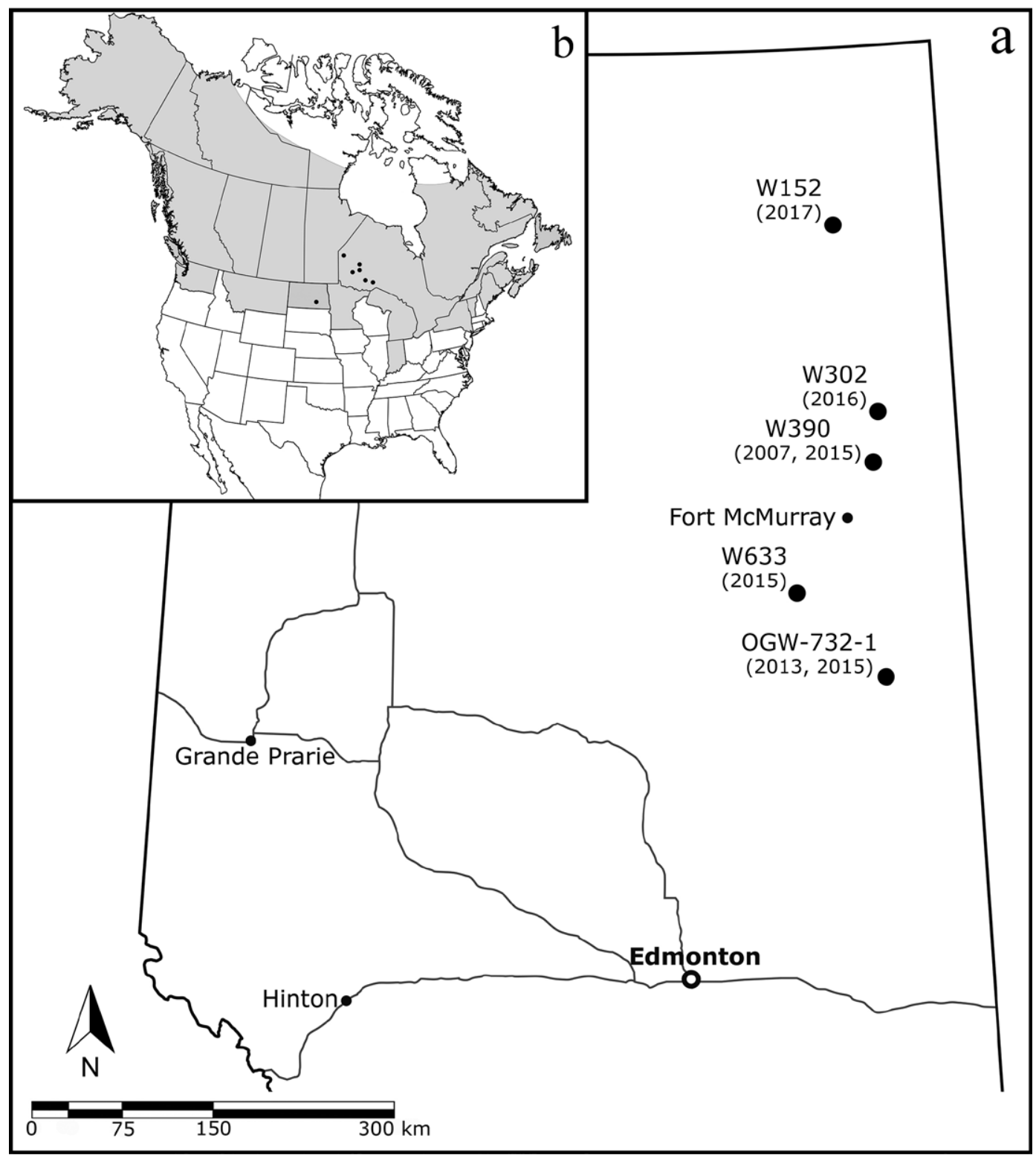

FigURE 1. a. Alberta Biodiversity Monitoring Institute wetland site locations where specimens of Valvata lewisi var. ontariensis have been documented in Alberta (large solid circles, collection years in parentheses). Inset map b. shows known range of Valvata lewisi (sensu stricto) in North America (shaded area) with historical collection records of $V$. lewisi var. ontariensis (solid circles).

standardized, publicly available methods (e.g., ABMI 2015, 2018). During routine taxonomic analysis of aquatic invertebrate samples collected by the ABMI in 2007 , we detected $12 \mathrm{~V}$. lewisi var. ontariensis specimens in samples obtained from a permanent wetland in the northeastern part of the province (ABMI site $\mathrm{W} 390 ; 57.26899^{\circ} \mathrm{N}, 110.72157^{\circ} \mathrm{W}$; Figure 1). Following this initial detection, several additional $V$. lewisi var. ontariensis specimens were subsequently recovered from ABMI samples collected from the initial detection site and four additional wetlands in the same region-W152 $\left(58.78107^{\circ} \mathrm{N}\right.$, $\left.110.86238^{\circ} \mathrm{W}\right), \mathrm{W} 302\left(57.80382^{\circ} \mathrm{N}, 110.65305^{\circ} \mathrm{W}\right)$, W633 $\left(55.97079^{\circ} \mathrm{N}, 112.23922^{\circ} \mathrm{W}\right)$, and OGW-732-1 $\left(55.25222^{\circ} \mathrm{N}, 110.91161^{\circ} \mathrm{W}\right.$; Figure 1) - for a total collection of 75 specimens. This sampling effort also 


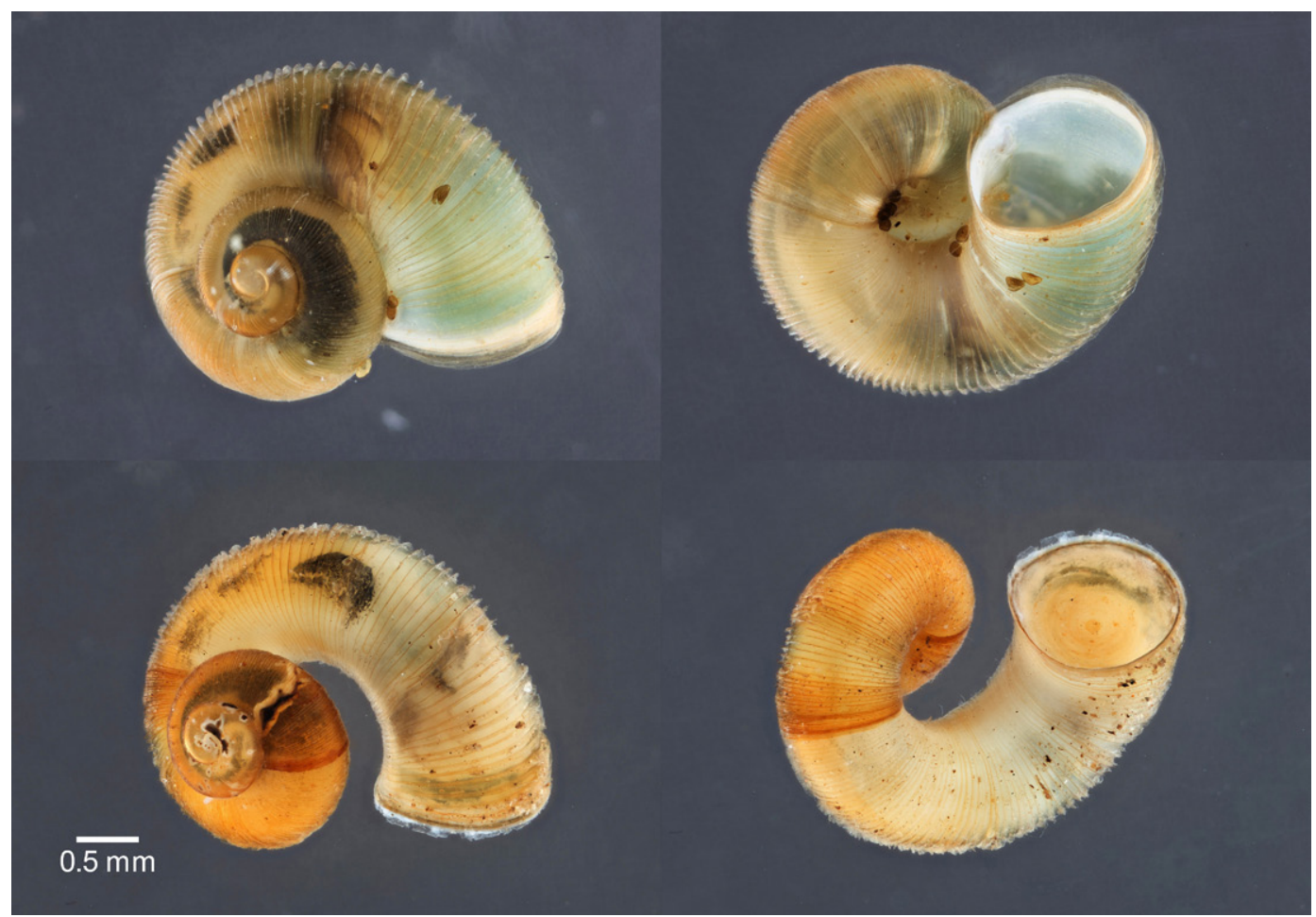

Figure 2. Dorsal and ventral views of Valvata lewisi (top) and Valvata lewisi var. ontariensis (bottom). Photos: Robert P. Hinchliffe.

revealed the co-occurrence of $V$. lewisi var. ontariensis and $V$. lewisi (sens. str.) at sites W390, W633, and OGW-732-1. Voucher specimens have been preserved in $80 \%$ ethanol and deposited in the invertebrate zoology collection at the Royal Alberta Museum in Edmonton, Alberta, Canada (ABMI.A.91, ABMI. A.5396, ABMI.A.11900, ABMI.A.15382, ABMI.A. 18222, and ABMI.A.30673).

Morphometric analyses of $V$. lewisi var. ontariensis revealed considerable variation in the degree of open coiling in Alberta specimens. Measurements showed a clear gradation in the ratio of open-coiled gap to aperture diameter in specimens from both W390 (0.04:1 to $0.22: 1$, mean $0.10: 1, n=16)$ and OGW732-1 (0.02:1 to $0.41: 1$, mean $0.13: 1, n=18)$, a pattern also noted, although not directly measured, by Baker (1931) when examining western Ontario specimens.

Our examination of intra- and inter-specific variability associated with the DNA barcode markers cytochrome c oxidase 1 (CO1) and internal transcribed spacer 2 (ITS2) for $V$. lewisi (sens. str.) and $V$. lewisi var. ontariensis specimens from sites W390 and OGW-732-1 indicated no genetic distinction between the two morphs. For CO1, the mean interspecific variation $( \pm \mathrm{SD}$ ) was $0.17 \% \pm 0.13$ with intraspecific genetic distances at $0.16 \% \pm 0.12$ for $V$. lewisi (sens. str.; $n=12$ ) and $0.16 \% \pm 0.14$ for $V$. lewisi var. ontariensis $(n=28)$. For ITS2, the mean interspecific variation $( \pm \mathrm{SD}$ ) was $0.07 \% \pm 0.14$ and the intraspecific genetic distance of $V$. lewisi (sens. str.; $n=10$ ) was $0.03 \% \pm 0.07$ and of $V$. lewisi var. ontariensis $(n=23)$ was $0.11 \% \pm 0.17$. DNA barcoding was conducted by the Canadian Centre for DNA Barcoding in Guelph, Ontario, Canada. Genetic sequences have been submitted to GenBank (CO1: MK721872 to MK721913, ITS2: MK721934 to MK721969).

Our detections of $V$. lewisi var. ontariensis constitute the first record of this morph in Alberta, Canada, and the first explicitly documented instances of cooccurrence of $V$. lewisi var. ontariensis with $V$. lewisi (sens. str.). Clarke (1973: 229) noted that loosely coiled specimens seemed to "occur also (rarely) in some apparently normal populations", but neglected to provide references or observational evidence for this statement. Furthermore, he suggested that the specimens he examined were uniform as all one morph or the other. Other published reports on this species do not make any mention of co-occurrence of the two morphs.

The taxonomic status of $V$. lewisi var. ontariensis as a valid subspecies has historically been uncertain (see Baker 1931; Clarke 1973, 1981; Burch 1982). 
The working definition of a subspecies is two or more populations of the same species from separate geographic locations with one or more distinguishing characters (Mayr 1942, 1982). The initial Ontario collections identified by Baker (1931) and later expanded on by Clarke (1973) were originally thought to be an isolated and distinct population of the open-coiled morph. Our concurrent collections of $V$. lewisi (sens. str.) and $V$. lewisi var. ontariensis clearly show that the two morphs can occur in the same water body. This, in addition to the lack of a CO1 or ITS2 barcode gap between the two morphs, supports the conclusion that $V$. lewisi ontariensis is a phenotypic morph of $V$. lewisi.

Despite the broad and common distribution of $V$. lewisi (sens. str.), the open-coiled morph has, thus far, been collected in only three isolated regions of North America. Given the widely spaced and seemingly isolated locations where $V$. lewisi var. ontariensis has been collected, it is possible that the opencoiled morph is the result of some unknown and possibly localized environmental factor. However, it is also possible that $V$. lewisi var. ontariensis is more common than collection records indicate and is simply difficult to detect during routine aquatic invertebrate surveys because of its small size and propensity to burrow into the upper layer of soft substrates (R.P.H. pers. obs.). Targetted sampling in other regions is needed to more fully understand the complete distribution of $V$. lewisi var. ontariensis. We recommend that future collections of open-coiled $V$. lewisi specimens be identified and labeled as $V$. lewisi var. ontariensis to allow for better tracking of the localities where this morph occurs and perhaps yield additional clues as to the possible source of open coiling.

\section{Author Contributions}

Writing-Original draft: R.P.H.; Writing-Review \& editing: R.P.H., C.T, and T.P.C.; Visualization: R.P.H.; Conceptualization: R.P.H. and T.P.C.; Investigation: R.P.H. and C.T.; Resources: C.T.; Formal analysis: R.P.H.

\section{Acknowledgements}

We thank Dr. Matthias Buck at the Royal Alberta Museum for assistance with the molecular analysis and valuable editorial suggestions on earlier versions of the manuscript. We also thank the Alberta
Biodiversity Monitoring Institute for providing additional data. This research was supported by the Alberta Biodiversity Monitoring Institute and the Royal Alberta Museum.

\section{Literature Cited}

ABMI (Alberta Biodiversity Monitoring Institute). 2015. Processing aquatic invertebrates (10017) version 2015-07-23. ABMI, Edmonton, Alberta, Canada. Accessed 12 November 2018. https://www.abmi.ca/home/ publications/351-400/396.

ABMI (Alberta Biodiversity Monitoring Institute). 2018. Wetland field data collection protocols (abridged version) 2018-05-07. ABMI, Edmonton, Alberta, Canada. Accessed 12 November 2018. https://www.abmi.ca/ home/publications/501-550/510.

Baker, F.C. 1931. Description of a new variety of Valvata lewisi Currier. Nautilus 44: 119-121.

Bright, R.C. 1981. A new record of Valvata sincera ontariensis F.C. Baker from Minnesota. Nautilus 95: 20.

Burch, J.B. 1982. Freshwater snails (Mollusca: Gastropoda) of North America. United States Environmental Protection Agency, Washington, DC, USA. EPA/600/3-82026 (NTIS PB82207168). Accessed 25 May 2018. https:// cfpub.epa.gov/si/si_public_record_Report.cfm?Lab= ORD\&dirEntryID $=32218$.

Clarke, A.H. 1973. The freshwater molluscs of the Canadian Interior Basin. Malacologia 13: 1-509.

Clarke, A.H. 1981. The Freshwater Molluscs of Canada. National Museum of Natural Science, Ottawa, Ontario, Canada.

Hanson, B.A., N.H. Euliss, Jr., and D.M. Mushet. 2002. First records of loosely coiled valve snail in North Dakota. Prairie Naturalist 34: 63-65.

Mayr, E. 1942. Systematics and the Origin of Species, from the Viewpoint of a Zoologist. Columbia University Press, New York, New York, USA.

Mayr, E. 1982. Of what use are subspecies? Commentary. Auk 99: 593-595.

NatureServe. 2017. Valvata species report. Accessed 27 April 2017. http://explorer.natureserve.org/servlet/Nature Serve? searchSciOrCommonName=Valvata.

Turgeon, D.D., J.F. Quinn, Jr., A.E. Bogan, E.V. Coan, F.G. Hochberg, W.G. Lyons, P. Mikkelsen, R.J. Neves, C.F.E. Roper, G. Rosenberg, B. Roth, A. Scheltema, F.G. Thompson, M. Vecchione, and J.D. Williams. 1998. Common and Scientific Names of Aquatic Invertebrates from the United States and Canada: Mollusks. Second Edition. Special Publication 26. American Fisheries Society, Bethesda, Maryland.

Received 2 April 2019

Accepted 24 December 2019 